\title{
Investigations for mechanical properties and biocompatibility of SS-316L implant prepared as rapid investment casting for batch production
}

\author{
JASPREET SINGH ${ }^{1}$, RUPINDER SINGH $^{2, *}$,, HARWINDER SINGH ${ }^{3}$ and \\ ANITA KAMRA VERMA ${ }^{4}$ \\ ${ }^{1}$ Mechanical Engineering Department, Lovely Professional University, Phagwara 144411, India \\ ${ }^{2}$ Production Engineering Department, Guru Nanak Dev Engineering College, Ludhiana 141006, India \\ ${ }^{3}$ Mechanical Engineering Department, Guru Nanak Dev Engineering College, Ludhiana 141006, India \\ ${ }^{4}$ Department of Zoology, Delhi University, Delhi 110007, India \\ e-mail: Rupindersingh78@Yahoo.Com
}

MS received 17 April 2017; revised 2 January 2018; accepted 18 January 2018; published online 12 May 2018

\begin{abstract}
In this work, a detailed procedure for the development of biomedical implant (SS-316L) by combining fused deposition modeling (FDM), chemical vapor smoothing (CVS), silicon molding (SM) and investment casting (IC) for batch production has been outlined. In spite of being biocompatible and bioactive within the body, the implant must possess good surface quality and dimensional accuracy along with sufficient hardness in order to reduce the wear inside the body. So in this research work, investigations have been made on the surface finish, dimensional accuracy and hardness of the implants by varying two controllable factors of the IC process (drying time of primary coating and mould thickness). The tolerance grades for the selected dimension of the casted implants were within the allowable range as defined in UNI EN 20286-I (1995) standard of ISO. The process capability indices $\left(\mathrm{C}_{\mathrm{p}}\right.$ and $\left.\mathrm{C}_{\mathrm{pk}}\right)$ values greater than 1.33 for the surface hardness and radial dimension indicated that the proposed process is statistically controlled. Further, in order to evaluate the biocompatibility, an in vitro study was conducted to ensure the attachment of mouse embryonic fibroblasts cells (NIH-3T3) to the casted samples. The results of invitro study indicated that samples were capable of supporting cell adhesion and cell proliferation and hence can be used for tissue engineering.
\end{abstract}

Keywords. Fused deposition modeling; chemical vapor smoothing; silicon molding; investment casting; biocompatibility; invitro analysis.

\section{Introduction}

In the last two decades, the demand for tailor made biomedical implants had been increased at high rates all around the world [1]. These implants must be biocompatible and bioactive within the body [2]. Also, they must possess properties like good surface quality, dimensionally accurate and sufficient hardness in order to reduce the wear inside the body $[3,4]$. Development of such implants using most appropriate route is the demand of today's world. Investment casting (IC) also known as 'precision casting' is the most widely used casting process to produce complex, intricate shaped and precision metallic components that require excellent surface finish and dimensional accuracy $[5,6]$. In traditional IC process, a metallic die is used to

*For correspondence make the sacrificial wax patterns. However, the high cost and time associated for fabricating the die makes the IC process economical only for mass production [7]. If the volume is low, then the cost associated for making the die makes the IC process expensive [7, 8]. In these cases, additive manufacturing (AM) techniques prove to be a feasible solution for the synthesis of specialized and customized products with reduced product development time $[9,10]$. Also, development in the area of rapid prototyping (RP) and image processing (IP) leads to the expansion of the applications of these technologies in the field of medical implantation [11].

Fused deposition modeling (FDM) is one of the most diffused RP techniques that bridged the gaps between conceptualization and realization of products [12]. In the process of FDM, materials like acrylonitrile butadiene styrene (ABS), polycarbonate or wax are heated to a semi-liquid state by the heaters present in FDM extrusion head [13] and then the head deposits the material in thin 
layers. Each layer bonds to the previous layer by particular material fabrication technology until the 3D physical model is built $[14,15]$. Rapid investment casting (RIC) is one of the biggest applications of FDM, where castings are prepared by utilizing 3D plastic model fabricated by FDM as sacrificial patterns in the traditional IC process $[15,16]$ and thus eliminate the expensive tooling required for making the patterns [17]. This application can speed up the production processes in aerospace, medical and micro-manufacturing industry having requirement of flexible designs with lower cost and shorter lead times [18]. However, the major drawback of FDM process is the poor surface quality and dimensional inaccuracy even for basic part geometries [19]. The poor surface quality of sacrificial pattern definitely affects the final surface finish of the casting in RIC process. Also, the poor surface finish of castings may lead to dimensional inaccuracy and post-operative complications if used for biomedical applications [12]. So, in order to improve the surface finish and dimensional accuracy of FDM prototypes, researchers employed various techniques such as optimization of input parameters, optimizing part build orientations, utilization of optimum slicing strategy, barrel finishing, etc. [20-25]. Further, some of the researchers highlighted that chemical vapor smoothing (CVS) technique drastically improve the surface finish of FDM fabricated ABS replicas with minimal variation in part dimensions [11, 19, 26, 27]. Also, the dimensions of ABS replicas fabricated by the combined process of FDM and CVS has been found to be consistent with the permissible range of tolerance grades as per ISO standard UNI EN 20286-I (1995) and DIN 16901 for plastic materials [28]. Further, RP technologies are not preferred for batch production due to high cost involved and also have limited range in terms of material selection [29]. This requires the need of developing rapid tooling (RT), which is an extension of RP. It is the technology that utilizes the $\mathrm{RP}$ and applies them to the manufacturing of various tools [30, 31]. Silicon molding (SM) is an established prototyping technique widely used in industry to produce wax patterns [32, 33] and various types of plastic parts due to high chemical resistance of silicon rubber and low interfacial energy of its surface. SM is a characterized by the use of a vacuum during the process of mould fabrication and the casting of plastic parts [34]. Some studies have been reported as an indirect approach for producing wax patterns via silicon rubber molding from RP based master pattern to reduce the costs associated with single-part or small-quantity production during the investment casting (IC) process [7]. Further, many researchers have successfully fabricated sacrificial wax patterns for IC process by room temperature vulcanized mould process [35-37] but hitherto, very less work has been reported to fabricate polyurethanes (PU) replicas that can be utilized as plastic based patterns in traditional IC process in order to improve the dimensional accuracy for complex and intricate shapes.

Harun et al [38] fabricated ABS patterns (solid as well as hollow) using FDM technique for IC process and observed that hollow pattern construction proved to be more viable than solid pattern construction in terms of dimensional accuracy, mould cleanliness and pattern. Singh et al [39] compared the dimensional accuracy of the hip joint prepared by IC process by varying the pattern material (conventional wax and $\mathrm{ABS}$ ) and number of slurry layers and concluded that ABS pattern with 8 number of slurry layers results into minimum deviation. Kumar et al [40] investigated the effect of selected parameters on the hardness of hip joint fabricated as hybrid IC and concluded that mold thickness and volume to surface area ratio of the casting play a significant role in deciding the microstructure and hardness of the castings. Singh et al [41] investigated the effect of mould thickness and drying time of primary coating on the dimensional accuracy of castings prepared as RIC and concluded that mould thickness affects the dimensional accuracy significantly. Further, the tolerance grades for the selected dimension of the castings were found to be acceptable as per the ISO standard UNI EN 20286-I (1995). In recent past some work has been reported to fabricate biomedical implant by combining FDM and IC in order to analyze its bio-compatibility. The samples prepared were also investigated for corrosion properties [42].

Also, literature review reveals that stainless steel (SS$316 \mathrm{~L}$ ) is the most widely used material for medical and dental applications due to its excellent mechanical and biomedical (bioactivity and biocompatibility) properties $[43,44]$. In traditional IC process, wax is used as a material for sacrificial pattern whereas plastic based patterns are used in RIC process. Since steam cannot wash off plastic based patterns like it does with wax in the autoclave, hence no autoclave is done in RIC process. In order to remove the plastic based pattern, the shell is placed into a flash fire furnace where temperature reach upwards of $2000{ }^{\circ} \mathrm{F}$ $\left(1093^{\circ} \mathrm{C}\right)$, and the pattern combusts, giving off gas and possibly leaving a small amount of ash in the hollow shell mould. Since the ash left in the mould is basically a form of carbon, it may affect the properties especially biocompatibility of the castings made of SS-316L material. So, investigations have to be performed to study the various properties of the casting produced from plastic based patterns. Further in this research work, experimental investigations had been carried out by varying two controllable factors of the IC process, namely drying time of primary coating and mould thickness on various properties such as surface roughness, dimensional accuracy and hardness of the castings prepared by this combined route. Also, the biocompatibility of the casted implants prepared by this route $(\mathrm{FDM}+\mathrm{CVS}+\mathrm{SM}+\mathrm{IC})$ had been evaluated by invitro testing. 


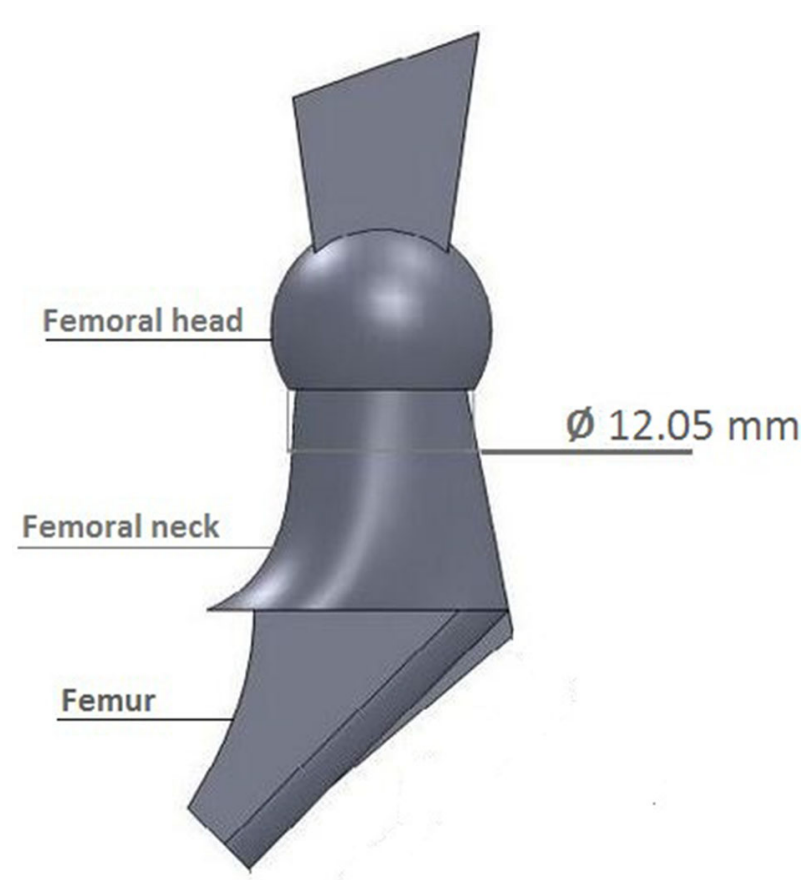

Figure 1. Benchmark component.

\section{Methodology}

In this research work, the most commonly used biomedical implant (hip joint) as shown in figure 1 has been selected as the benchmark component. The CAD model of the component had been made using CREO 2.0 software and then converted into .STL file. The .STL file serves as an input to the FDM machine to fabricate 3D model of acrylonitrile butadiene styrene (ABS) material followed by the CVS process to enhance the surface finish. It has been observed that CVS process dramatically improves the surface finish of ABS replicas. The results were in line with the observations made by other investigators [19, 26]. After that, multiple prototypes of PU material were produced by silicon molding (SM) process in order to reduce the cost of RP. IC process begins with joining the PU prototypes to a tree followed by number of layers of stucco coating of ceramic material for imparting strength to the mould (figure 2). Baking of the mould is then carried out in a furnace at around $900^{\circ} \mathrm{C}$. During the baking process, the PU replicas suddenly come out of the mould in the gaseous state and leave the shell for pouring the molten metal. Before pouring, compressed air was passed through the shell for removing any ash content that left during the baking process. Castings were produced with a biocompatible grade of stainless steel (SS-316L). The complete methodology of the study has been shown in figure 3 .

The literature related to IC process indicated that mould thickness and drying time of primary coating are the main factors that affect the properties of the castings [9, 40, 41]. In the IC process, the only way to control the thickness of the mould is by controlling the number of ceramic slurry layers. Higher the number of slurry layers more will be the thickness of the mould. Observation made from pilot experimentation indicates that by using less than 7 number of slurry layers, the IC shell gets cracked while pouring the molten metal. This was due to the thermal shock exerted by the molten metal on the walls of the mould. Further, as the number of layers increases beyond 9, the shells become too
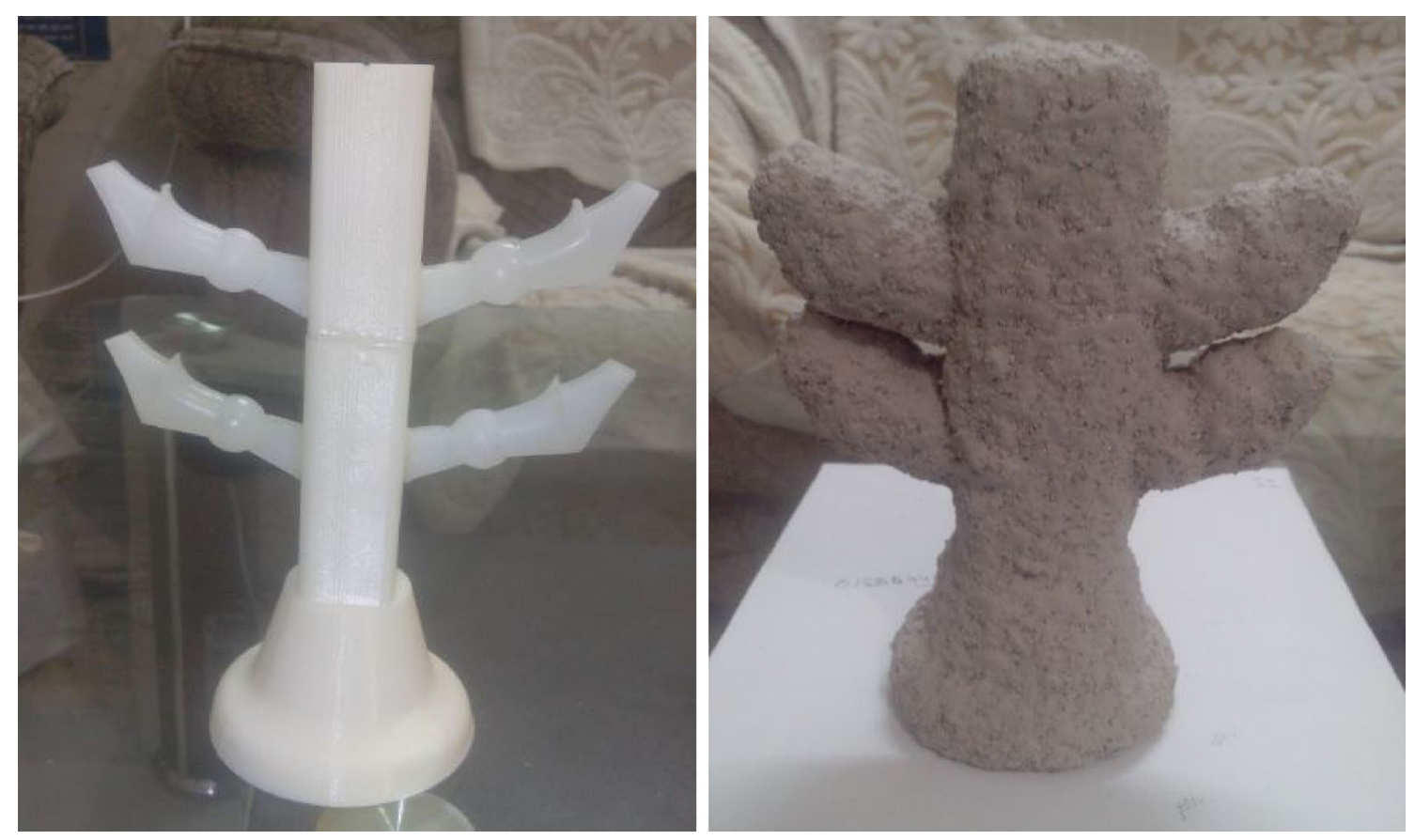

Figure 2. PU prototypes attached to tree followed by stucco coating of ceramic. 
Table 1. Parameters and their levels for IC process.

\begin{tabular}{lccrr}
\hline & & & \multicolumn{2}{c}{ Levels } \\
\cline { 3 - 5 } Parameters & Symbol & Unit & 1 & 2 \\
\hline Drying time of primary coating & A & Min & 330 & 360 \\
Mould thickness & B & Number of layers & 7 & 8 \\
\hline
\end{tabular}

Table 2. Control log of experimentation.

\begin{tabular}{|c|c|c|c|c|c|}
\hline $\begin{array}{l}\text { Exp. } \\
\text { no. }\end{array}$ & $\begin{array}{c}\text { A } \\
(\min )\end{array}$ & $\begin{array}{l}\mathrm{B} \text { (number of } \\
\text { layers) }\end{array}$ & $\begin{array}{l}\text { Average surface roughness, } R_{a} \\
(\mu \mathrm{m})\end{array}$ & $\begin{array}{l}\text { Average dimensional deviation, ' } \Delta \mathrm{d} \text { ' } \\
(\mathrm{mm})\end{array}$ & $\begin{array}{l}\text { Average hardness } \\
\text { (HV) }\end{array}$ \\
\hline 1 & 330 & 7 & 2.148 & 0.262 & 186 \\
\hline 2 & 330 & 8 & 2.246 & 0.192 & 169 \\
\hline 3 & 330 & 9 & 2.104 & 0.137 & 151 \\
\hline 4 & 360 & 7 & 1.898 & 0.252 & 189 \\
\hline 5 & 360 & 8 & 1.805 & 0.205 & 175 \\
\hline 6 & 360 & 9 & 1.756 & 0.142 & 158 \\
\hline 7 & 390 & 7 & 1.634 & 0.234 & 221 \\
\hline 8 & 390 & 8 & 1.515 & 0.190 & 177 \\
\hline 9 & 390 & 9 & 1.593 & 0.124 & 161 \\
\hline
\end{tabular}

heavy in weight and the heat transfer rate of molten metal reduces thus affecting the hardness of the castings. Similarly, during the pilot experimentation, moisture content was observed in the moulds when the drying time was set below $300 \mathrm{~min}$. This results in lack of strength of the mould. Also, the moisture content causes formation of small pores and certain other defects during the baking of the moulds and thus affects the quality of the castings. Based on the results of pilot experimentation, levels selected for the two parameters in IC process have been shown in table 1. Full factorial approach has been used to plan and analyze the experiments.

\section{Experimentation}

Control $\log$ of experimentation along with the results of surface finish, dimensional accuracy and hardness of the castings have been shown in table 2 . In this work, surface roughness $\left(R_{a}\right)$ and dimensional deviation $(\Delta d)$ has been taken to represent the surface finish and dimensional accuracy, respectively. Surface roughness $\left(R_{a}\right.$ value) of all the castings has been measured at femur part by Mitutoyo $\mathrm{SJ}-210$ roughness tester at $0.5 \mathrm{~mm} / \mathrm{s}$ stylus speed and cutoff length at $0.25 \mathrm{~mm}$. One radial dimension (as shown in figure 1) of all the PU replicas and corresponding castings was measured by coordinate measuring machine (CMM) and deviation has been measured. The surface hardness of the casted hip joints was measured by using Vickers hardness tester (HVS-1000BVM) as per ASTME-384 standard. In order to minimize the variation, three readings were taken for each response and the average of the three values was considered as the final output. Figure 4 shows the casted components and figures 5-7 indicate the variation of output response with the experiment number.

Figure 5 indicates that ' $R_{a}$ ' value improves with increase in drying time of primary coating. This was due to the removal of moisture present in the ceramic shell with increase in drying time of primary coating. The minimum value of ' $\mathrm{R}_{\mathrm{a}}$ ' was observed with drying time of $390 \mathrm{~min}$. Mould thickness has very little influence on the surface roughness of the castings.

Figure 6 indicates that ' $\Delta \mathrm{d}$ ' decreases with increase in mould wall thickness and was minimum with 9 number of layers. This was due to the fact that lesser mould wall thickness results in higher heat transfer rate and ultimately more shrinkage occurs. As the number of layers increases, heat transfer rate as well as shrinkage decreases which results in lesser deviation. Drying time of primary coating has negligible effect on dimensional deviation. The maximum shrinkage of approximately $2.2 \%$ has been observed in the selected radial dimension of the castings produced with 7 number of layers.

Figure 7 indicates that hardness value decreases with increase in mould wall thickness i.e., as the number of layers of ceramic material increases, the hardness value decreases. This was due to the fact that with increase in number of slurry layers, heat transfer rate and ultimately cooling rate of the casting decreases which in turn reduces the hardness value. Higher the cooling rate more will be the hardness of the casting. Further, with increase in drying time of primary coating, the hardness value increases slightly. This was due to the fact that by increasing the drying time, the moulds were strengthened properly due to 


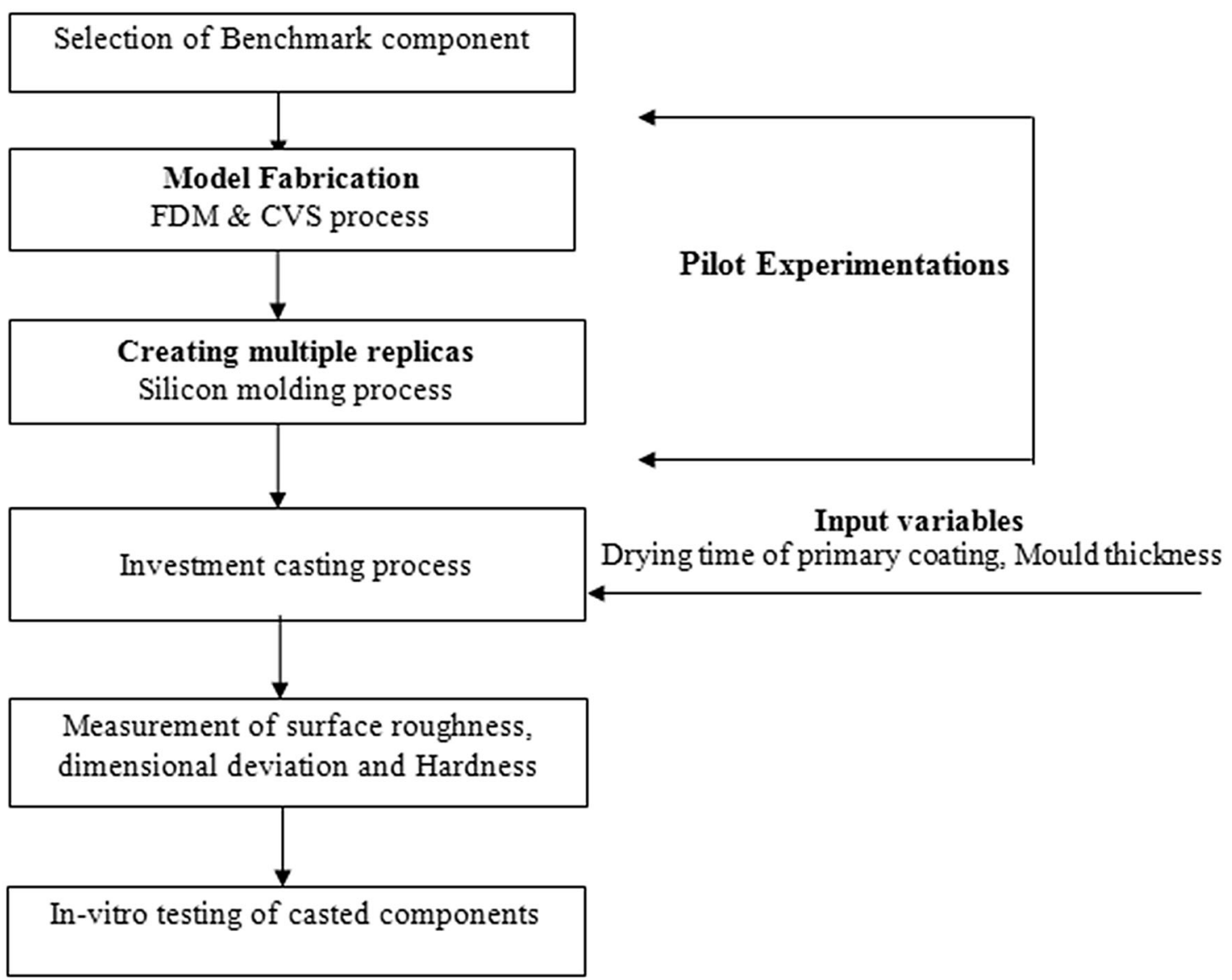

Figure 3. Methodology of the study.

the removal of any moisture present in them and consequently increases the hardness value. However, the effect on hardness with increases in drying time was not significant.

\section{Invitro study}

Further, in order to evaluate the biocompatibility of casted samples, an invitro study was conducted to ensure the attachment of fibroblast cells to the fabricated structures. The specimens of size $5 \mathrm{~mm} \times 0.5 \mathrm{~mm}$ were first sterilized in autoclave conditions at $15 \mathrm{psi}, 121^{\circ} \mathrm{C}$ for $15 \mathrm{~min}$ and thereafter under ultraviolet light for $30 \mathrm{~min}$ prior to start of the experiment. Mouse embryonic fibroblasts cells $(\mathrm{NIH}-$ 3T3) were maintained in adherent cultures. Cells of a 90 per cent confluency were trypsinized and re-suspended in serum-containing medium and these first passage cells were seeded at a density of $10 \times 10^{3}$ cells/well in a six-well plate for designed specimens and placed in a 5 percent $\mathrm{CO}_{2}$ humidified $37^{\circ} \mathrm{C}$ incubator. Briefly, cells were maintained in fully supplemented medium, i.e., Dulbecco's modified Eagle's medium with 10 per cent fetal bovine serum, $2 \mathrm{mM}$ l-glutamine and antibiotics $(100 \mathrm{U} / \mathrm{ml}$ penicillin and 100 $\mathrm{g} / \mathrm{ml}$ streptomycin). Culture medium was changed every two to three days for one week, till cells became confluent. The specimen was transplanted to a new, well-supplemented with complete media (second passage) and checked for proliferation. This is performed to estimate the number of adherent cells in a culture well to estimate the proportion of the surface which is covered by cells. Figure 8 shows growth of NIH3T3 cells in designed specimens. Fluorescently labeled cell samples were imaged using a Nikon Eclipse TE2000 inverted laser scanning confocal microscope with operating software. The results exhibit growth of fibroblast cells and were found to be proliferating over the designed specimens. They were found capable of supporting cell adhesion and cell proliferation. These results suggest that these carriers are suitable for cell culture and can be used for tissue engineering.

\section{Results and discussion}

\subsection{Calculation of tolerance grades}

In today's manufacturing scenario, the calculation of the tolerance (IT) grade becomes very important when one has to commercialize a manufacturing process. In order to find 


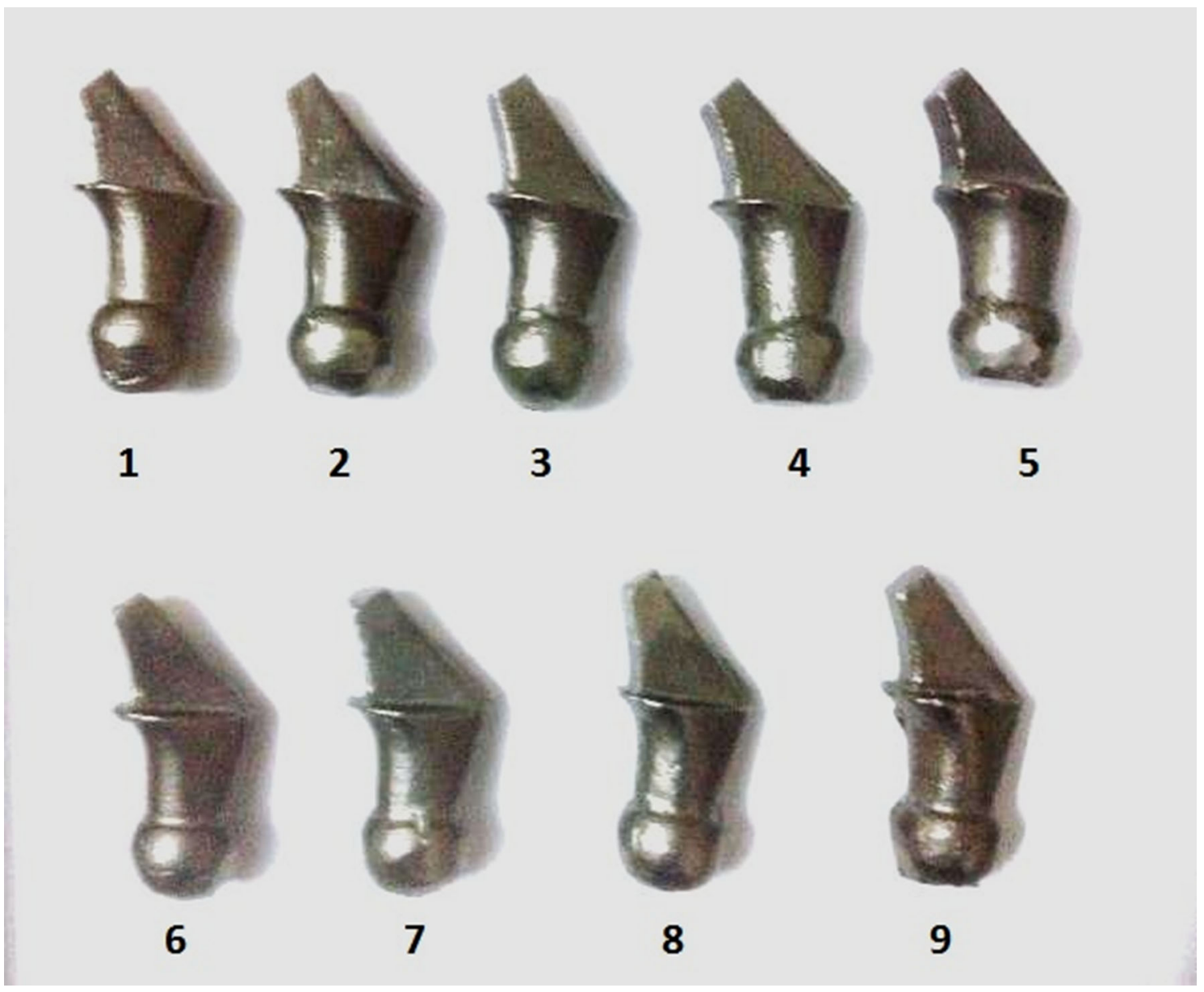

Figure 4. Specimens after casting.

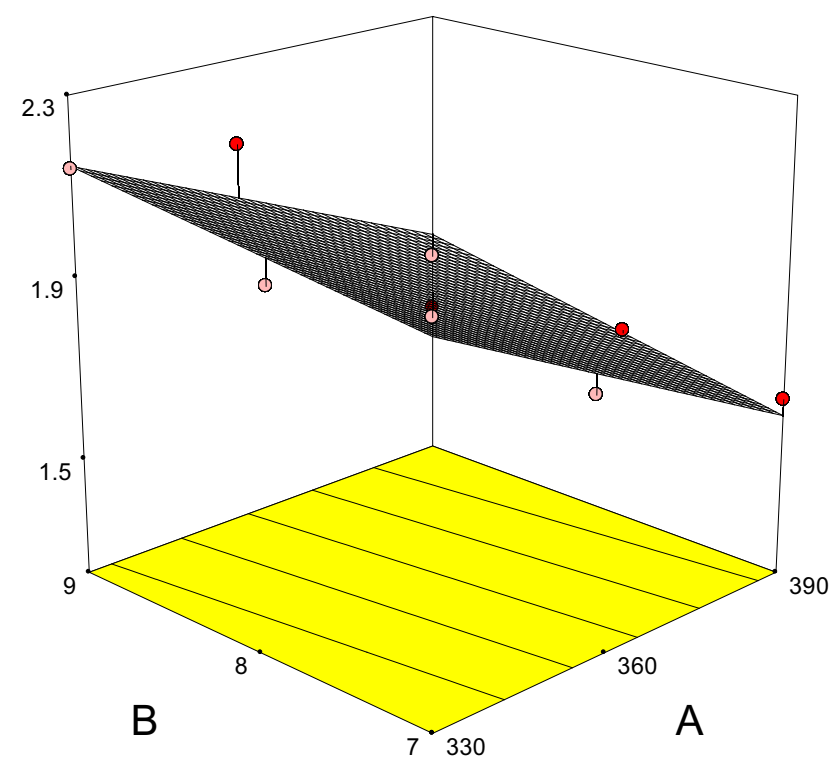

Figure 5. Variation of surface roughness.

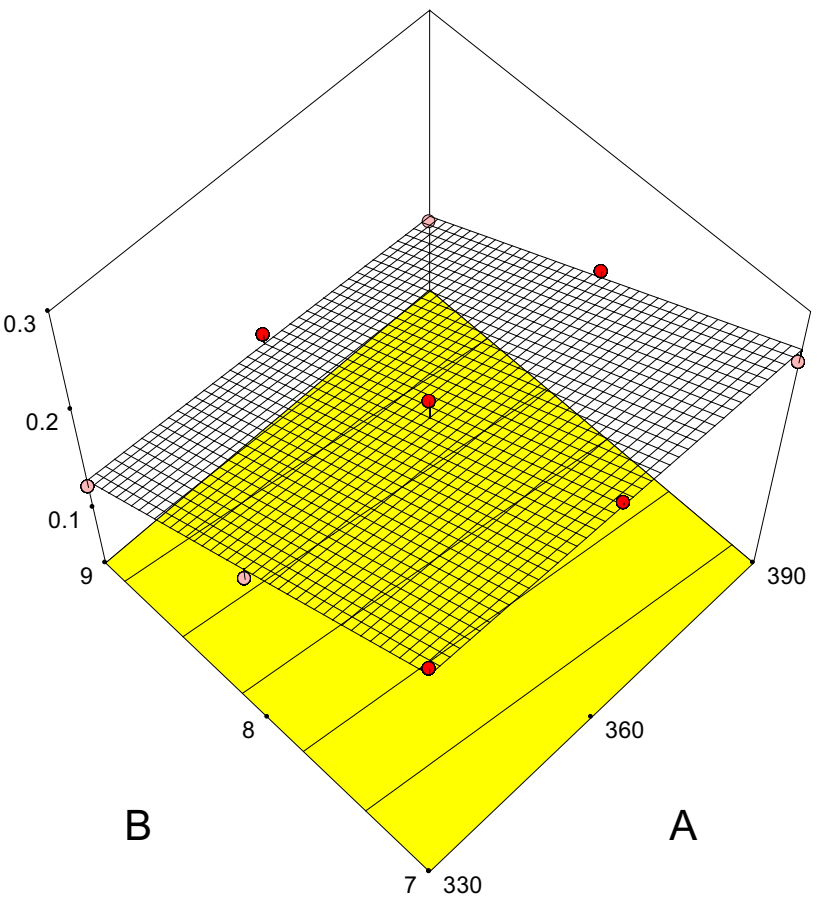

Figure 6. Variation of radial dimension. 


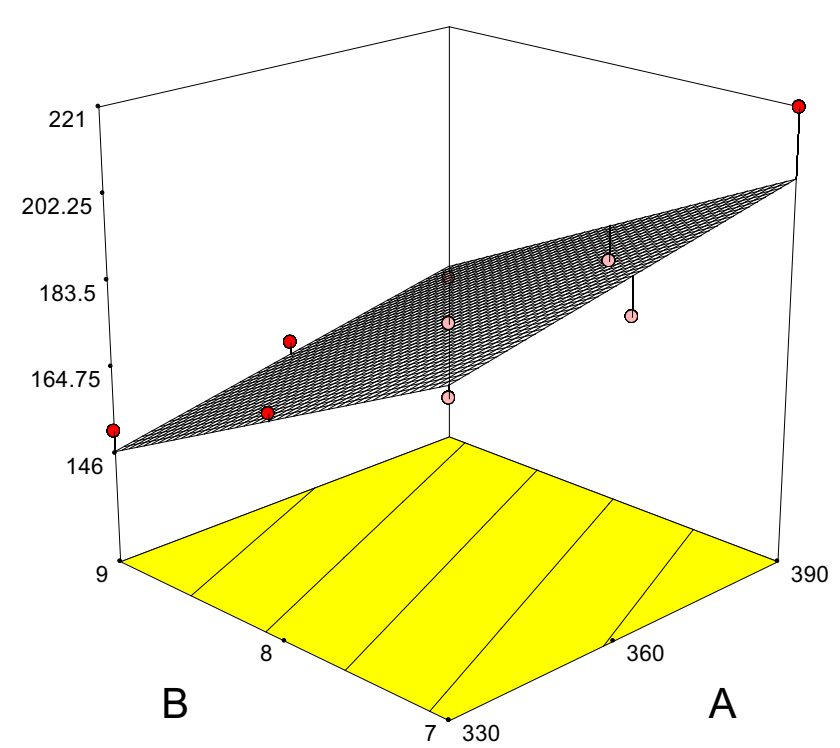

Figure 7. Variation of hardness.

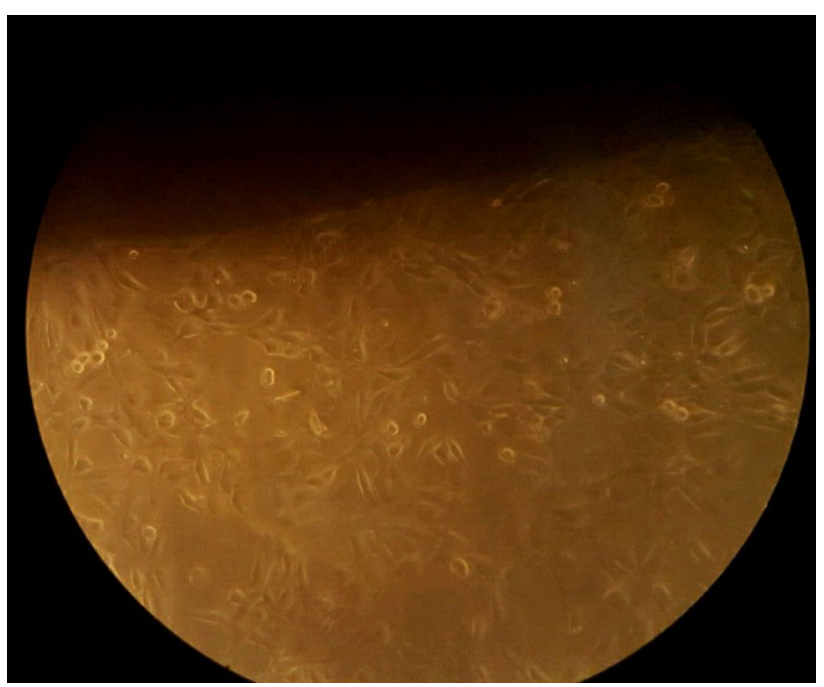

Figure 8. Growth of NIH-3T3 cells at 10X.

the tolerance grades, first the measured dimensions have been utilized to calculate the tolerance unit ' $n$ ' that derived from fundamental tolerance ' $\mathrm{i}$ ', as outlined in UNI EN 20286-I (1995) standard of ISO. The fundamental tolerance ' $i$ ' and tolerance unit ' $n$ ' is calculated as follows [10]:

$$
\begin{aligned}
& \mathrm{i}=0.45 \sqrt[3]{D}+0.001 \mathrm{D} \\
& \mathrm{n}=1000\left(\frac{D_{N}-D_{M}}{i}\right)
\end{aligned}
$$

where ' $\mathrm{D}$ ' is the geometric mean of range of nominal size, $D_{N}$ is the nominal dimension, $D_{M}$ is the measured dimension, ' $\mathrm{i}$ ' is the fundamental tolerance in $\mu \mathrm{m}$.
Table 3. Calculations of IT grades.

\begin{tabular}{cccc}
\hline $\begin{array}{l}\text { Exp. } \\
\text { no. }\end{array}$ & $\begin{array}{c}\text { Radial dimension } \\
(\mathrm{mm})\end{array}$ & $\begin{array}{c}\text { Tolerance value 'n' in } \\
(\mu \mathrm{m})\end{array}$ & $\begin{array}{c}\text { IT } \\
\text { grade }\end{array}$ \\
\hline 1 & 11.788 & 241.99 & IT13 \\
2 & 11.858 & 177.33 & IT13 \\
3 & 11.913 & 126.54 & IT12 \\
4 & 11.798 & 232.75 & IT13 \\
5 & 11.845 & 189.34 & IT13 \\
6 & 11.908 & 131.15 & IT12 \\
7 & 11.816 & 216.13 & IT13 \\
8 & 11.860 & 175.49 & IT13 \\
9 & 11.926 & 114.53 & IT12 \\
\hline
\end{tabular}

In this research work, the selected radial dimension has been taken as nominal dimension. The standard basic step for dimension $\left(\mathrm{D}_{1}=12.050 \mathrm{~mm}\right)$ is $10-18 \mathrm{~mm}$. In experiment 1 (see table 2), the value of ' $n$ ' for the selected linear and radial dimension is calculated as follows:

$$
\begin{aligned}
\mathrm{D} & =(10 \times 18)^{1 / 2}=13.416 \mathrm{~mm} \\
\mathrm{i} & =0.45(13.416)^{1 / 3}+0.001(13.416)=1.0827 \mu \mathrm{m} \\
\mathrm{n} & =1000(12.050-11.778) / 1.0827=241.99
\end{aligned}
$$

Similarly, the tolerance unit for all the experiments (as per table 2) has been calculated and the obtained IT grades have been shown in table 3 . Further, it has been observed that (see table 3) the measured dimension in all the experiments is less than the nominal dimension. This was due to the shrinkage that occurs during solidification of the casting as the metal changes state from liquid to solid. The shrinkage is generally compensated by providing shrinkage allowance to the pattern. The results indicate that the IT grades of the castings prepared by this RIC process are within the allowable range as defined in UNI EN 20286-I (1995) standard of ISO.

\subsection{Process capability analysis}

In order to ensure that the process is repeatable and statistically controlled, 12 samples were casted by taking drying time of $390 \mathrm{~min}$ and number of layers as 9. These levels were selected only for the reason that the radial deviation was minimum (refer table 2) at these parameter settings. The observations of surface hardness and radial dimension of castings have been shown in table 4. After that the $C_{p}$ and $C_{p k}$ values of the process and histogram of observed values for surface hardness and radial dimension have been obtained by 'Process Capability Wizard 2016' software. Figures 8 and 10 indicate the histogram of the observed values along with $C_{p}$ and $C_{p k}$ values for the surface hardness and radial dimension, respectively. The prerequisite for computing $\mathrm{C}_{\mathrm{p}}$ and $\mathrm{C}_{\mathrm{pk}}$ is that the process is required to be under statistical control and that the data are 
Table 4. Observations of selected dimension.

\begin{tabular}{rcc}
\hline Sl. no. & Surface hardness $(\mathrm{HV})$ & Radial dimension $(\mathrm{mm})$ \\
\hline 1 & 167 & 11.924 \\
2 & 164 & 11.926 \\
3 & 163 & 11.923 \\
4 & 159 & 11.919 \\
5 & 164 & 11.922 \\
6 & 166 & 11.925 \\
7 & 170 & 11.925 \\
8 & 168 & 11.921 \\
9 & 167 & 11.920 \\
10 & 163 & 11.923 \\
11 & 164 & 11.921 \\
12 & 164 & 11.925 \\
\hline
\end{tabular}
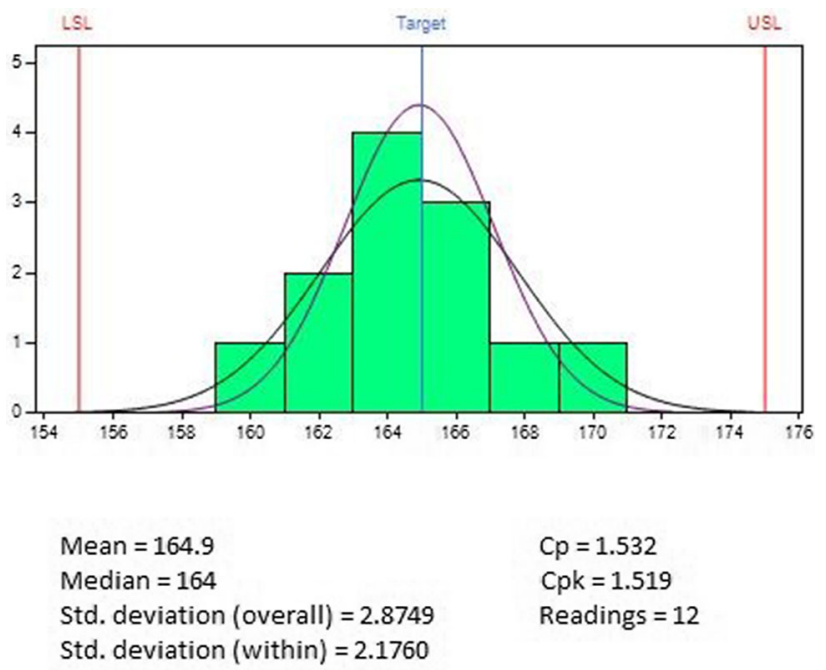

Figure 9. Histogram of observed values for surface hardness.

normally distributed $[45,46]$. Since the value of both $C_{p}$ and $\mathrm{C}_{\mathrm{pk}}$ for the hardness as well as radial dimension has been found to be greater than 1.33 , it indicated that the process is statistically controlled [47]. Further, normal probability plot for the selected responses (see figures 912) indicates that the data are normally distributed. The observed values are plotted on the $\mathrm{X}$-axis against a theoretical normal distribution (z-scores) on the $\mathrm{Y}$-axis [46]. A regression line is drawn from these $\mathrm{XY}$ pair which shows points closer to the regression line and thus indicating a good fit. These results are in line with the observations made by other investigators [48, 49].

\section{Conclusions}

From this research work, the following conclusions have been drawn.

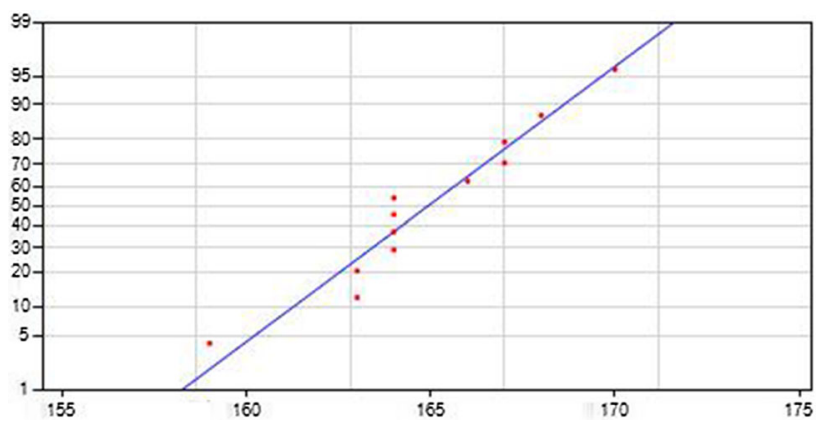

Figure 10. Normal distribution curve of observed values for surface hardness.

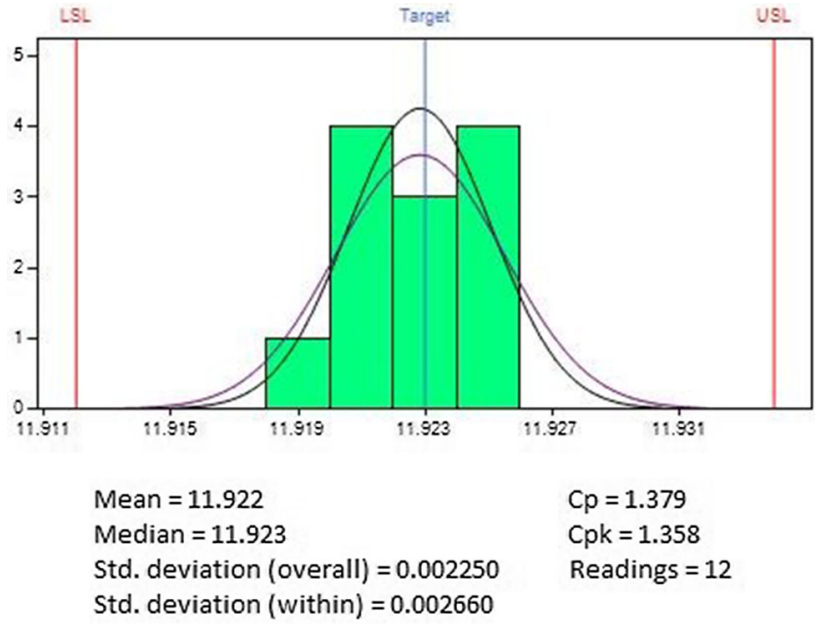

Figure 11. Histogram of observed values for radial dimension.

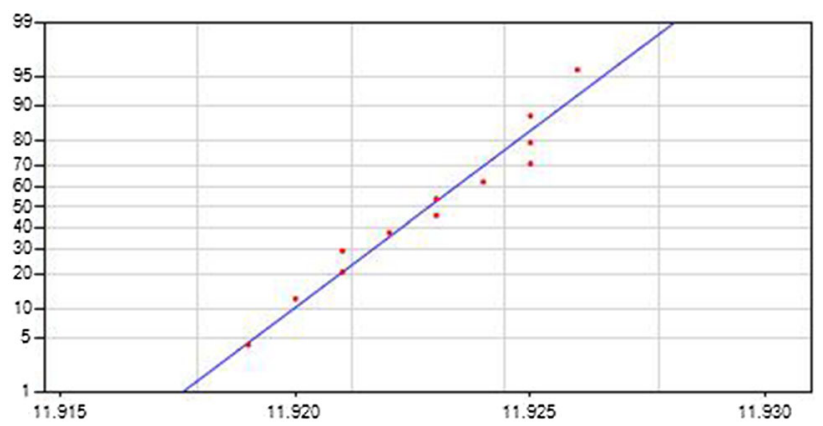

Figure 12. Normal distribution curve of observed values for radial dimension.

- The combined route of FDM, CVS, SM and IC has been found to be feasible for the development of biomedical implant for batch production.

- Drying time of primary coating affects the surface finish significantly and ' $\mathrm{R}_{\mathrm{a}}$ ' value improves with increase in drying time of primary coating. 
- Dimensional deviation decreases with increase in mould wall thickness due to the fact that as the number of layers increases, heat transfer rate as well as shrinkage of the castings decreases which results in lesser deviation.

- Surface hardness decreases with increase in mould wall thickness due to the fact that with increase in number of slurry layers, heat transfer rate and ultimately cooling rate of the casting decreases which in turn reduces the hardness value.

- The tolerance grades for the selected dimension of the casted implants were within the allowable range as defined in UNI EN 20286-I (1995) standard of ISO.

- The $\mathrm{C}_{\mathrm{p}}$ and $\mathrm{C}_{\mathrm{pk}}$ value greater than 1.33 for the surface hardness and radial dimension indicated that the proposed process is statistically controlled.

- Further, the samples casted by this combined route (FDM+CVS+SM+IC) were found to be capable of supporting cell adhesion and cell proliferation and hence can be used for tissue engineering.

\section{Acknowledgements}

The authors are thankful to Manufacturing Research Lab (Guru Nanak Dev Engineering College, Ludhiana) and Department of Zoology, Delhi University for providing the research facilities. The authors are also highly thankful to Dr Jatender Pal Singh (Assistant Director DGQA, MoD) for providing the technical support.

\section{References}

[1] Singh R and Singh G 2013 Process capability analysis for replication of FDM based patterns by vacuum moulding in biomedical applications. In: Proceedings of International Conference on Smart Technologies for Mechanical Engineering (STME-2013), October 26-27, Delhi Technological University, Delhi

[2] Gibson I, Cheung L K, Chow S P, Cheung W L, Beh S, Savalani M M and Lee S H 2006 The use of rapid prototyping to assist medical applications. Rapid Prototyp. J. 12: 53-58

[3] Gu P and Li L 2002 Fabrication of biomedical prototypes with locally controlled properties using FDM. Ann. CIRP 51(1): 181-184

[4] Roath M 2012 Analysis of the microstructure and hardness of a direct digital manufactured metal used for an acetabular cup implant. In: Proceedings of the National Conference on Undergraduate Research (NCUR) 2012, Weber State University, Ogden Utah, March 29-31, 2012

[5] Liu Q, Sui G and Leu M C 2002 Experimental study on the ice pattern fabrication for the investment casting by rapid freeze prototyping. Comput. Ind. 48: 181-197

[6] Amira S, Dube D and Tremblay R 2011 Method to determine hot permeability and strength of ceramic shell moulds. $J$. Mater. Process. Technol. 211(8): 1336-1340
[7] Cheah C M, Chua C K, Lee C W, Feng C and Totong K 2005 Rapid prototyping and tooling techniques: a review of applications for rapid investment casting. Int. J. Adv.Manuf. Technol. 25(3-4): 308-320

[8] Pattnaik S, Karunakar B and Jha P K 2012 Developments in Investment casting process-A review. J. Mater. Process. Technol. 212: 2332-2348

[9] Singh R, Kapoor P and Singh S 2015 Effect of process parameters on hardness of hip joint developed by combining fused deposition modelling and investment casting. Trans. Indian Inst. Metal. 68(5): 723-728

[10] Singh J P and Singh R 2009 Investigations for statistically controlled rapid casting solution of lead alloys using three dimensional printing. J. Mech. Eng. Sci. (Proc. IME Part C) 223: 2125-2134

[11] Singh J, Singh R and Singh H 2017 Investigations for improving the surface finish of FDM based ABS replicas by chemical vapor smoothing process: a case study. Assembl. Autom. 37(1): 13-21

[12] Singh J, Singh R and Boparai K S 2016 Mathematical modeling of surface roughness for vapour processing of ABS parts fabricated with fused deposition modeling. J. Manuf. Process. 24: 161-169

[13] Chhabra M and Singh R (2011) Rapid casting solutions: a review. Rapid Prototyp. J. 17(5): 328-350

[14] Noorani R 2005 Rapid prototyping-principles and application. New Jersey: John Wiley \& Sons Inc

[15] Upcraft S and Fletcher R 2003 The rapid prototyping technologies. Assembl. Autom. 23(4): 318-330

[16] Kumar P, Ahuja I P S and Singh R 2012 Application of fusion deposition modelling for rapid investment casting - a review. Int. J. Mater. Eng. Innov. 3: 204-227

[17] Kumar P, Singh R and Ahuja IPS 2015 Investigations on dimensional accuracy of the components prepared by hybrid investment casting. J. Manuf. Process. 20(3): 525-533

[18] Budzik G 2010 Geometric Accuracy of aircraft engine blade models constructed by means of the generative rapid prototyping methods FDM and SLA. Adv. Manuf. Sci. Technol. 34(1): 33-43

[19] Garg A, Bhattacharya A and Batish A 2016 On surface finish and dimensional accuracy of FDM parts after cold vapor treatment. Mater. Manuf. Process. 31(4): 522-529

[20] Sood A K, Ohdar R K and Mahapatra S S 2009 Improving dimensional accuracy of fused deposition modelling processed part using grey Taguchi method. Mater. Des. 30: 4243-4252

[21] Mohamed O A, Masood S H and Bhowmik J L 2016 Optimization of fused deposition modeling process parameters for dimensional accuracy using I-optimality criterion. Measurement 81: 174-196

[22] Chakraborty D, Reddy A, Roy B and Choudhury A 2008 Extruder Path generation for curved layer fused deposition modeling. Comput. Aid. 40: 235-243

[23] Nuñez P J, Rivas A, García-Plaza E, Beamudb E and SanzLobera A 2015 Dimensional and surface texture characterization in Fused Deposition Modelling (FDM) with ABS plus. Procedia Eng. 132: 856-863

[24] Boschetto A, Giordano V and Veniali F 2013 Surface roughness prediction in fused deposition modelling by neural networks. Int. J. Adv. Manuf. Technol. 67: 2727-2742 
[25] Boschetto A and Bottini L 2015 Surface improvement of fused deposition modelling parts by barrel finishing. Rapid Prototyp. J. 21(6): 686-696

[26] Galantucci L M, Lavecchia F and Percoco G 2009 Experimental study aiming to enhance the surface finish of fused deposition modeled parts. Ann. Manuf. Technol. 58: 189-192

[27] Singh J S, Singh R and Boparai K S 2016 Parametric optimization of fused deposition modeling and vapour smoothing processes for surface finishing of biomedical implant replicas. Measurement. 94: 602-613

[28] Singh J, Singh R and Singh H 2016 Repeatability of linear and radial dimension of ABS replicas fabricated by fused deposition modelling and chemical vapor smoothing process: a case study. Measurement. 94: 5-11

[29] Boparai K, Singh R and Singh H 2016 Development of rapid tooling using fused deposition modeling: a review. Rapid Prototyp. J. 22(2): 281-299

[30] Rosochowski A and Matuszak A 2000 Rapid tooling-the state of art. J. Mater. Process Technol. 106: 191-198

[31] Ma S, Gibson I, Balaji G and Hu Q J 2007 Development of epoxy matrix composites for rapid tooling applications. $J$. Mater. Process. Technol. 192(193): 75-82

[32] Smith B J, St Jean P and Duquette M L 1996 A comparison of rapid prototype techniques for investment casting Be-Al. In: Proceedings of Rapid Prototyping and Manufacturing Conference, Dearbon, MI, 23-25, pp 1-11

[33] Chung S, Park S, Lee, I, Jeong H and Cho D 2005 Replication techniques for a metal micro-component having real 3D shape by microcasting process. Microsyst. Technol. 11: 424-428

[34] Tang Y, Tan Fuh W K, Loh J Y H, Wong H T, Thian Y S and Lu S C H 2007 Micro Mould fabrication for micro-gear via vacuum casting. J. Mater. Process. Technol. 192-193: 334-339

[35] Yarlagadda P and Hock T S 2003 Statistical analysis on accuracy of wax patterns used in investment casting. $J$. Mater. Technol. 138: 75-81

[36] Rahmati S, Akbari J and Barati E 2007 Dimensional accuracy analysis of wax patterns created by RTV silicon rubber molding using Taguchi approach. Rapid Prototyp. J. 13(2): $115-122$

[37] Zamani J, Hemati M H and Morsaluie R 2014 An experimental comparison on dimensional accuracy of wax patterns of gas turbine blades produced by rapid tooling. Arab. J. Sci. Eng. 39: 7289-7297
[38] Harun W S W, Safian S and Idris M H 2008 Evaluation of ABS patterns produced from FDM for investment casting process. WIT Trans. Eng. Sci. 64: 319-328

[39] Singh R, Singh S and Singh G 2014 Dimensional accuracy comparison of investment castings prepared with wax and ABS patterns for bio-medical application. Procedia Mater. Sci. 6(Icmpc): 851-858

[40] Kumar P, Singh R and Ahuja I P S 2016 Experimental investigations on hardness of the biomedical implants prepared by hybrid investment casting. J. Manuf. Process. 21: 160-171

[41] Singh J, Singh R and Singh H 2017 Dimensional accuracy and surface finish of biomedical implant fabricated as rapid investment casting for small to medium quantity production. J. Manuf. Process. 25(1): 201-211

[42] Singh D, Singh R, Boparai K S, Farina I, Feo L and Verma A K 2018 In-vitro studies of SS 316 L biomedical implants prepared by FDM, vapor smoothing and investment casting. Compos. Part B. 132: 107-114

[43] El-Hadad S, Khalifa W and Nofal A 2015 Surface modification of investment cast-316L implants: Microstructure effects. Mater. Sci. Eng. 48: 320-327

[44] Akmal M, Hussain M A, Ikram H, Sattar T, Jameel S, Kim, J U, Khalid F A and Kim J U 2015 In-vitro electrochemical and bioactivity evaluation of SS316L reinforced hydroxyapatite functionally graded materials fabricated for biomedical implants. Ceram. Int. 42(3): 3855-3863

[45] Singh R 2012 Effect of work piece volume on statistically controlled rapid casting solution of aluminum alloys using three dimensional printing. Mater. Manuf. Process. 27(4): $377-382$

[46] Singh R 2014 Process capability analysis of fused deposition modelling for plastic components. Rapid Prototyp. J. 20(1): 69-76

[47] Macků M and Horáček M 2012 Applying RP-FDM technology to produce prototype castings using the investment casting method. Arch. Found. Eng. 12(3): 75-82

[48] Singh R and Singh G 2017 Investigations for modelling hardness of biomedical implant while replication of FDM based patterns by vacuum moulding. Sadhana. 42(3): 327-333

[49] Garg P, Singh R and Ahuja I P S 2017 Multi-objective optimization of dimensional accuracy, surface roughness and hardness of hybrid investment cast components. Rapid Prototyp. J. 23(5): 845-857 